\title{
Histeria: Historia De La Sexualidad Femenina
}

\author{
Hysteria: Female's Sexuality History \\ Histeria: Historia Da Sexualidade Feminina
}

\author{
Elena Ma . Fernández Laveda, Águeda Fernández Martínez, Irene Belda Antón \\ Diplomada Universitaria en Enfermería. Máster Salud, Mujer y Cuidados, Escuela Universitaria de Enfermería. \\ Universidad de Murcia
}

Cómo citar este artículo en edición digital: Fernández Laveda, E.Ma; Fernández García, A. y Belda Antón, I. (2014) Histeria: Historia De La Sexualidad Femenina. Cultura de los Cuidados (Edición digital) 18, 39. Disponible en: http://dx.doi.org/10.7184/cuid.2014.39.08>

Correspondencia: Elena Ma Fernández Laveda. C/ Antonio Machado, 19 CP 30420 Calasparra (Murcia)

Correo electrónico: efl94v@gmail.com

Recibido: 23/10/2013; Aceptado: 16/02/2014

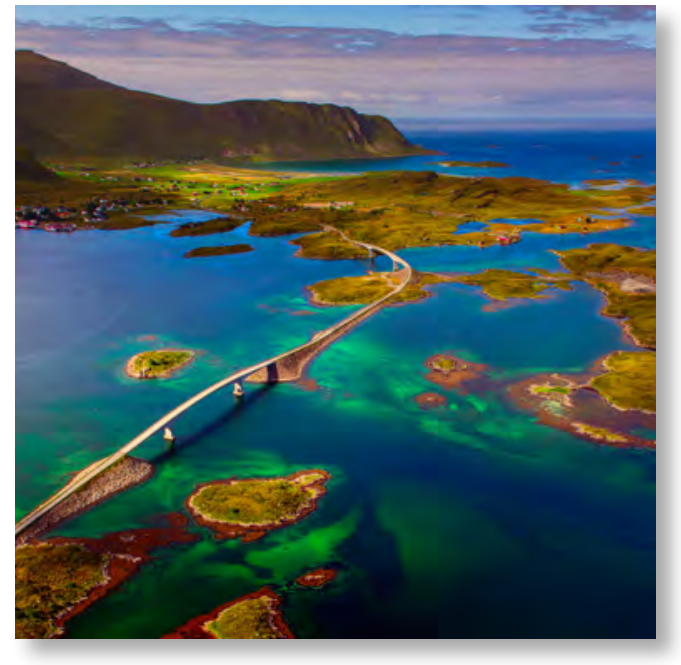

ABSTRACT

Introduction: Hysteria comes from hysteron, a Greek word that means Uterus. From there it follows the feminization of the disease and the link with the prototype of perfect woman at that time.

Objective: Study the relationship between Hysteria and female sexuality through different historical periods.

Materials and Methods: Literature Review in Databases.

Results: Different studies try to explain the etiology and symptomatology of Hysteria. It calls our attention that some women were treated in a clandestinely way: pelvic massages.

Conclusions: Analysis of the legacy of women who suffered from the stigmatization of being branded as hysterical women at present. How we see hysteria today: meaning and connotations.

Keywords: Hysteria, Hysterical Suffocation, History, Woman. Female's Sexuality History.

\section{RESUMO}

Introduçao: Etimológicamente o termo Histeria vem da palavra grega Hysteron que significa Utero. Por isto deduzimos, a feminizaçao da doença e a vinculaçao a um ideal de mulher historicamente vigente.

Objectivos: Dar a conhecer a Hisetria e o laço que a associa com a sexualida de feminina durante diferentes épocas históricas.

Material e método: Revisao bibliográfica sistemática em bases de dados.

Resultados: Diferentes rocionomentos tratam de esclarecer a etiología, sintomatología da doença. Resultado chamativo, por otro lado, o tratamento clandestino que algunas mulheres histéricas recebem: o massagem pelvico.

Análise do legado das mulheres que sofrem estigamtiazaçao de serem acusadas de 
histéricas desde una visao actual. Como vemos a histgeria hoje: significado e conotaçoes.

Palavras Chave: Histeria, sufocaçao histericas, Historia, mulher, Historia Da Sexualidade Feminina.

\section{RESUMEN}

Introducción: Etimológicamente el término Histeria proviene de la palabra griega Hysteron que significa Útero. De esto deducimos, la feminización de la enfermedad y la vinculación al ideal de mujer históricamente vigente.

Objetivos: Dar a conocer la Histeria y el lazo que la une con la sexualidad femenina a lo largo de diferentes épocas históricas.

Material y método: Revisión Bibliográfica Sistemática en Bases de datos.

Resultados: Diferentes racionamientos tratan de esclarecer la etiología y sintomatología de la enfermedad. Resulta llamativo, por otro lado, el tratamiento clandestino que algunas mujeres histéricas reciben: los masajes pélvicos.

Conclusiones: Análisis del legado de las mujeres que sufrieron la estigmatización de ser tachadas de histéricas desde una visión actual. Cómo vemos la Histeria hoy: significado y connotaciones.

Palabras clave: Histeria, Sofocaciones Histéricas, Historia, mujer.

\section{INTRODUCCIÓN}

La Histeria, desde el momento de su nacimiento como patología, se considera una enfermedad claramente femenina. Las mujeres ven cómo su Útero se considera estigma de su imperfección y, por ende, factor de riesgo altamente predisponente para el padecimiento de este mal.

Esta Revisión Bibliográfica no pretende hacer apología del Feminismo, no demanda cas- tigo ni persecución hacia el hombre en general o particular, simplemente hace un recorrido histórico por la vivencia de las mujeres aquejadas de Histeria. Mujeres que ven cómo su patología se centra en el hecho en sí mismo de tener Útero y, cómo a lo largo de los siglos, éste pasa de viajar por todo su cuerpo a convertirla en bruja o hasta a enmascarar traumas ocultos que dejan entrever una sexualidad enfermiza.

Éste es un viaje a través de la Historia, a través del tiempo, tomados de la mano de las mujeres que vivieron denostadas por sus Úteros, de las cadenas que las ataban y de cómo los científicos a lo largo de los siglos han tratado de desentrañar lo que significa ser una mujer diferente, una mujer histérica. El Objetivo fundamental que plantea este trabajo es dar a conocer al público en general el significado histórico de la Histeria, así como su oculta vinculación con la sexualidad y vivencias femeninas.

\section{MATERIAL Y MÉTODO}

Nuestro estudio se plantea como una Revisión Bibliográfica que pretende la investigación de Fuentes Primarias y Secundarias para un abordaje de la Histeria que nos permita no sólo adentrarnos en la patología sino en lo que se deduce de ésta: La visión que los eruditos tienen de las mujeres, los comportamientos aceptables y la forma de entender la sexualidad femenina.

Las Fuentes Primarias se eligen por su trascendencia y sobretodo por la representatividad que adquieren al tratarse de material de estudio de las Facultades de Medicina del siglo XIX. El examen al que se someten dichos textos permite conocer el sentir de la comunidad científica sobre la Histeria y así poder leer entre líneas acerca de las mujeres y su sexo. Los textos pertenecen a 1862 y 1864 . Las Fuentes Secundarias, por otro lado, se seleccionan por 
su veracidad y utilidad en la contextualización de la Histeria en las diferentes Épocas Históricas. De esta forma, se pueden contraponer los conceptos de mujer ideal y sexualidad a lo largo del tiempo, a través de lo que fue y lo que es ser mujer. Para su obtención se realiza una búsqueda en las Bases de Datos CUIDEN, DIALNET, PUBMED, CINAHL y SCIELO usando las palabras clave Histeria, Sofocación Histérica, Historia, Mujer, Hysteria, Hysterical Suffocation, History, Women. De los textos obtenidos, se acotan los publicados desde 1968 a 2012.

\section{RESULTADOS}

\section{Los orígenes de la Histeria: Sentando las ba-} ses de la Enfermedad del Útero.

El término Histeria proviene del vocablo griego "hysteron" y significa Útero. En la Antigüedad, se instauran las bases ideológicas de la Histeria como enfermedad propia del Útero. A partir de aquí, son numerosas las teorías que tratan de explicar su etiología y sus numerosas manifestaciones. Una de las más curiosas es la Teoría del Útero Errante, que trata de dar respuesta a la sintomatología a través de la movilidad del órgano por todo su cuerpo: Por ejemplo, si el Útero se desplazaba y aplastaba los pulmones producía ahogos, si lo hacía sobre el corazón, los síntomas eran palpitaciones.

La clave de este vagar orgánico es la imperfección del cuerpo femenino, caracterizado por la humedad y frialdad, que hacía que el Útero migrara en busca de los lugares más confortables de su anatomía. Médicos tan reputados como Hipócrates y Galeno ya mencionan este concepto en sus escritos y lo usan para solventar la patología femenina. Como tratamiento médico, se limitaban a "alimentar" al Útero con toda clase de sustancias para que éste volviera a su lugar. Es muy llamativa la otra parte de la cura de la Histeria, que pasa por casar de forma inmediata a aquella mujer que fuese virgen e incluso a la que había enviudado. Parece más que clara la relación entre sexualidad e Histeria, que, de manos de la Iglesia, procura la redención del mal que habita en las mujeres a través del ministerio sagrado del matrimonio.

\section{- Edad Media y Renacimiento: Obediencia o redención a través de la hoguera.}

En la Edad Media, la vida de las mujeres se estructura en función de las necesidades de los demás. Se establece un patrón de mujeres estáticas y sumisas que son educadas para cumplir deberes prefijados por una sociedad patriarcal. Sus roles fundamentales son los de esposa y madre, irremediablemente ligada a un varón que vele por ella: padre, esposo, hermano... Por otro lado, aquellas mujeres que no se ajustan a estos roles son consideradas una amenaza, algo intimidante que hay que eliminar.

La sintomatología psíquica u orgánica de la Histeria se traduce en infamia que se ha apoderado de las mujeres: Son brujas que se dejan influenciar por el Diablo. En este momento, el síndrome histérico deja de verse desde el prisma científico: Se inicia el escrutinio desde la lente de la religión. La mujer diferente se reviste de ropajes de pecado y es deber de la Iglesia deshacerse de los malos ejemplos persiguiendo y juzgando a cualquier mujer que actúe de forma incoherente según lo establecido.

Durante el Renacimiento, la Histeria pierde su halo demoníaco: Pasa de ser un tema tratado en Iglesias y con los Sacerdotes como "sanadores" del mal, para volver al campo de la Medicina. La etiología religiosa da paso a la Ciencia y a los científicos, que tratan de desentrañar el misterio de la mujer diferente: la mujer histérica. 


\section{El siglo XIX: Las histéricas de la alta socie- dad.}

El siglo XIX se caracteriza por el aislamiento femenino, las mujeres ven cómo la sociedad construye muros de sobriedad, religiosidad, conservadurismo y moralidad alrededor de ellas. La sexualidad femenina se encierra en la alcoba conyugal cuyo único objetivo moralmente aceptado es la reproducción. Al mismo tiempo, la Histeria adquiere mayor preponderancia como diagnóstico médico y llena los sanatorios, convertidos ahora en hervideros de mujeres histéricas.

De este modo, la Medicina se ve obligada a admitir una nueva realidad: La mujer posee instinto sexual y necesita las relaciones sexuales para mantenerse sana. Si bien este reconocimiento marca una diferencia sustancial con la Edad Antigua, nuevamente la sexualidad femenina viene ligada a la salud reproductiva. La importancia de un Útero sano para la reproducción hace que Medicina e Iglesia se den la mano (aunque sea a regañadientes).

Pese al largo periplo de la Histeria como patología, no hay consenso en cuanto a qué es, manifestaciones o etiología. Sólo hay una idea común a lo largo de los siglos: Cualquier comportamiento extraño en una mujer es compatible con la patología histérica.

Los sabios y científicos escudriñan cada rincón del cuerpo y la mente femeninos para tratar de comprender la enfermedad femenina que más quebraderos de cabeza ha dado a los grandes pensadores de la Historia, para ello emplearán los métodos que trae la nueva ciencia.

Como ejemplos de esta nueva ciencia, analizamos en mayor profundidad dos textos científicos que corresponden a esta época: “Tratados Prácticos de las enfermedades de los órganos sexuales de la mujer" de F. W. Scanzo-



ni (1862) y "Lecciones Clínicas de las Enfermedades de la Mujer” de Bedford (1864).

En "Tratados Prácticos de las enfermedades de los órganos sexuales de la mujer" de F. W. Scanzoni (1862), el autor define la Histeralgia como una "Neuralgia de Útero". Es una enfermedad rara caracterizada por un dolor continuo que incomoda de forma permanente con una sintomatología inespecífica a nivel físico que va desde gordura o anemia a escozor en genitales, latidos que atravesaban la pelvis, estrechez anormal de la vagina o la secura extraordinaria de sus paredes.

Es muy habitual este tipo de diagnóstico durante el siglo XIX, aunque el propio autor duda de que todas las pacientes diagnosticadas de Histeria sean realmente enfermas de este tipo, puesto que en las autopsias no se encuentran síntomas orgánicos.

Bedford, en el tratado "Lecciones Clínicas de las Enfermedades de la Mujer", en cambio, sí que da una etiología clara de su Histerismo, que es motivada por una alteración nerviosa refleja por la irritación de los órganos genitales. Además nos habla sobre factores de riesgo, situaciones, lugares y rasgos en el carácter que hacen que determinadas mujeres sean más 
proclives a la enfermedad: “... las mujeres que nacen y se crían en ciudades populosas, en medio de las escitaciones de toda clases..., “... la privación de las relaciones sexuales, sobretodo en las que fue habitual...", "presentándose con más frecuencia en as son hijas de madres histéricas...", "el clima cálido [...], puesto que las alteraciones del aparato genital son más comunes en las regiones tropicales". También observa que hay más tendencia a la enfermedad en la pubertad que, por ejemplo, en la menopausia.

Bedford apuesta también por la posibilidad del padecimiento masculino de la Histeria y cita para ejemplificarlo un caso. En éste, el paciente presenta una sintomatología claramente motivada por la masturbación excesiva aunque, gracias a su inteligencia y a su buen sentido, los fenómenos histéricos desaparecen de forma rápida y sencilla.

Ambos autores convienen en la inespecifidad de los síntomas observados, lo que nos lleva de nuevo a la idea de que cualquier síntoma inexplicado desde un punto de vista orgánico, tiene cabida dentro esta enfermedad. El Útero parece ser el cajón desastre en el que se engloba casi cualquier problema de salud que una mujer pueda tener.

Tanto Bedford como Scanzoni coinciden en dar una breve pincelada final sobre la cuestión relativa al sexo: Scanzoni nos habla sobre una de sus pacientes, que mejora al casarse y Bedford nos comenta que en el tratamiento, es muy importante encontrar "una voluntad que la domine" y "obtener un tratamiento moral".

En estos textos, sin embargo, no habla de otro tratamiento que se realizaba dentro de la consulta médica: El Masaje Pélvico. En él, los médicos masajean el clítoris de sus pacientes hasta producirles un "paroxismo histérico", que hoy simplemente denominaríamos orgas- mo. Obviamente el masaje pélvico no curaba la Histeria, de hecho, las supuestas enfermas acudían a los médicos para obtener el placer que no recibían en sus casas. Pero esta actividad se volvió en muchos casos tediosa.

\section{El otro tratamiento de la Histeria}

Se considera que el origen de la Histeria era la frustración sexual femenina pero no se hacía nada para promover una sexualidad más gratificante y plena. Como consecuencia, el número de mujeres histéricas aumenta alarmantemente y con éstas, el número de tratamientos que intentan sanarlas. Entre ellos adquiere gran relevancia el masaje pélvico, que lleva a muchas mujeres a la consulta para obtener su paroxismo histérico. De hecho, la afluencia de féminas en tratamiento llega a ser tal, que los médicos empiezan a inventar todo tipo de artefactos que ahorren tiempo y trabajo. Joseph Mortimer Granville patenta en la década de 1880 un aparato electromecánico de forma fálica como instrumento terapéutico para efectuar el “masaje pélvico" de forma más fácil, rápida y limpia. Al entenderse como herramienta médica se usa única y exclusivamente en la Consulta: Amigos, ha nacido el primer vibrador. Este nuevo invento tuvo tal notoriedad que se comercializó para llevarlo al gran público. Las mujeres podían realizarse el masaje pélvico ellas mismas en la comodidad de sus casas evitando así acudir a la consulta. Eso sí, siempre con la ayuda de su marido y en un contexto puramente médico.

Su difusión a través de curiosas campañas publicitarias acrecienta este nuevo furor vibratorio hace. Se promocionan como una forma de mantener a las mujeres relajadas y contentas: "La vibración proporciona vida y vigor, fuerza y belleza", "El secreto de la juventud se ha descubierto en la vibración”. Su éxito llega a 
tal extremo que algunos modelos incluyen un recambio adaptable que convierte el vibrador en una batidora. Curioso cuanto menos.

Al final de esta época, algunos médicos declaran sentirse frustrados al haberlo probado todo y no alcanzar los resultados esperados, puesto que las enfermas nunca llegaban a curarse. Fue el primer mal al que los médicos no pudieron encontrar una explicación totalmente somática, por ello, tratan de buscar algo que por fin le dé una explicación global. En ese momento se empieza a introducir el término "neurosis".

\section{Siglo XX: El cambio.}

La mujer se considera inferior biológicamente al hombre, por tanto éstas no podían votar, estudiar o simplemente pasear solas. Una mujer no podía realizar ninguna tarea parecida a las del hombre por el riesgo de volverse histérica: Una pregunta incómoda en un momento inapropiado puede ser considerada un indicio de la patología.

En los planteamientos del Socialismo, se establece como uno de sus principios básicos el de igualdad. Se instituye como un derecho fundamental tanto para hombres como para mujeres, esto reactiva procesos sociopolíticos que fomentan la participación de las mujeres, defendiendo sus derechos al trabajo y a la educación. Su participación en Sindicatos y diferentes partidos políticos contribuyó a la consolidación de las organizaciones feministas.

Hacia finales del siglo XIX y principios del $\mathrm{XX}$, muchas mujeres conforman movimientos sufragistas que exigían los derechos civiles para éstas. Allí su demanda principal era el derecho al voto. A través de la obtención de éste se esperaba conseguir los demás.

Coincidiendo con todo esto y con la aparición de los movimientos feministas, los diagnósticos de histeria decayeron progresivamente.
Freud, en su "Estudios sobre la Histeria", adopta la expresión "Histeria de Conversión" para designar un cuadro en el que los síntomas somáticos representan la resolución simbólica de un conflicto inconsciente. Señala que la aparición del síntoma viene determinada por la obtención de una ganancia secundaria.

El autor parte de los extraño de la heterogeneidad de la sintomatología y que no se encuentre correlato ni fuente orgánica: Anestesias sensoriales, contracturas, parálisis, tics, vómitos, anorexia, perturbaciones de la visión, alucinaciones, convulsiones... Todos se engloban dentro de su "Teoría Traumática de la Histeria” para, enumerando los síntomas, permitan diagnosticar a las mujeres de forma precoz $y$, a partir de ello, tratar de curarlas mediante sesiones de hipnosis y regresión. Se abre así una nueva vía de investigación, en la que los síntomas histéricos son indicio de un conflicto psíquico inconsciente.

Todo esto da lugar a la desaparición de Histeria como diagnóstico médico para sustituirse por el "Trastorno de Conversión o Somatomorfo". Como la antigua Histeria, sigue siendo más frecuente en mujeres y personas de bajo status económico, su inicio se da en la edad adulta y su debut puede ser repentino tras un conflicto o gradual.

\section{CONCLUSIONES: LA HERENCIA DE LA HISTERIA.}

La moralidad y la tradición como pauta del comportamiento femenino es una constante a lo largo de la Historia. En general, se espera que la mujer sea sumisa, abnegada y obediente, ya que no está bien visto que la mujer muestre sus pasiones de forma abierta.

Las restricciones y convencionalismos sociales coartan sus libertades y, entre ellas, la sexual: La mujer no tiene derecho a desear. 
Las relaciones sexuales se enmarcan dentro de la función reproductiva $y$, fuera de esto, son tachadas de indecorosas. El cambio viene de mano de los movimientos sufragistas, que promueven la revolución y siembran la semilla de la libertad y la igualdad entre hombres y mujeres.

Los fenómenos histéricos acompañan a las mujeres a lo largo de todo este periplo, intentando dar respuesta a la patología femenina de una forma científica, revistiendo los prejuicios masculinos de ropajes de erudición: El sujeto de experimentación siempre es femenino mientras que son hombres los que definen y describen los comportamientos anómalos fruto de su patología.

Curiosamente la estela de la Histeria perdura en nuestros días: Se usa el término Histeria también como sinónimo de nerviosismo o excitación extrema determinando además que la persona histérica es aquélla que no sabe lo que quiere o que cambia de parecer muy rápido, sin razón o sin ningún motivo aparente. Igualmente, en algunas culturas, se entiende como histérica aquella mujer que es capaz de seducir sin ningún tipo de interés romántico o sentimiento de amor. A la luz de lo anterior, el carácter negativo que todavía hoy se asocia a esta palabra así como su estrecha vinculación a la mujer.

Otro modo de ver el calado actual de la Histeria es analizando la filmografía, ya que la información audiovisual queda fijada en nuestra mente impregnando opiniones e interpretaciones de la realidad. Analizando algunos ejemplos observaremos cómo el cine ha tratado el histerismo femenino, para comprobar el mensaje que se transmite en nuestros días.

En "Mujeres al borde de un ataque de nervios" de Pedro Almodóvar se retrata a mujeres capaces de cualquier cosa por retener al hom- bre. Su obsesión por ser amadas es tal, que las lleva a cometer locuras con la excusa de no poder vivir sin amor. Esto motiva que se las califique como desquiciadas o histéricas.

Woody Allen en "Vicky, Cristina, Barcelona”, representa a María Elena como: "Una española con carácter, nerviosa, histérica y con muy mal genio". No hay una definición clara, pero se intuye el carácter negativo del adjetivo.

"Hysteria" narra en clave de ficción cómo se inventó el vibrador como forma médica de atender a los pacientes de forma rápida y eficaz. En contraposición, en "Un método peligroso", se muestra la dramática vivencia de una mujer que padece Histeria. Quedan claramente retratadas todas las fases de la patología: Desde su inicio, con toda la sintomatología asociada a la enfermedad y la crisis en su máximo apogeo, hasta el tratamiento psicoanalítico de Freud y Jung y la curación completa. Es muy ilustrativa su visión de la mujer histérica y todos los padecimientos que trae aparejados.

Como deducimos de esto, mujer e Histeria siguen unidas en perenne matrimonio incluso en el siglo XXI. Ya no entendida quizás como enfermedad, pero sí como algo relativo a la mujer y que marca su historia y la de sus derechos y libertades. Arrastramos la evocación mordaz y satírica hacia la mujer que levanta la voz y se hace oír.

Pero, pese a este injusto y negativo vínculo establecido entre Mujer e Histeria, nuestras antepasadas nos regalan un generoso tesoro: Poder ser consideradas seres sexuados y sexuales. No sólo somos mujeres por ser anatómicamente diferentes al hombre, por el hecho maravilloso de tener un Útero sino que además tenemos instinto sexual y deseamos como cualquier hombre.

$\mathrm{Y}$ ya un órgano no basta única y exclusivamente para definir lo que es una mujer sino 
que, gracias a nuestras predecesoras, mujeres histéricas que fueron casadas a la fuerza, galvanizadas, tachadas de locas, herejes, brujas, impuras o simplemente no consideradas como individuos con capacidad de raciocinio, hoy podemos disfrutar de todos nuestros derechos y libertades, incluyendo la libertad sexual.

\section{BIBLIOGRAFÍA}

- elmundo.es salud (2007) La realidad de la Histeria [Artículo], elmundo.es salud. Disponible en: <http: // www. Elmundo.es/ elmundosalud/ 2007/ 04/ 13/ neurociencia/ 116462216. html> [Consultado el día 2. 3. 2013]

- History House (2005) Why only women get hysterical [Artículo], Historyhouse. Disponible en <http:// www. Historyhouse. com/ in_history/ hysteria/> [Consultado el día 26. 2. 2013]

- Errázuriz Vidal, P. (2012) Misoginia romántica, psicoanálisis y subjetividad femenina. Prensas Universitarias de Zaragoza, Zaragoza

- Freud, S. (1895) Escritos sobre la Histeria. Alianza Editorial, Madrid

- Flores- Ayffán Santana, Z. E. (2010) Mujeres al borde de un ataque de nervios. Almodóvar: sumergido en el mundo femenino, Acta de diseño 9, V Encuentro Latinoamericano de Diseño, Buenos Aires

- Fraile Bravo, M; Tirado Altamirano, F; Prieto Moreno, J; Hernández Neila LM; Magdaleno Bravo E; Sánchez Solís L. (2012) Naturalis historia de Plinio: concepción y terapéutica. A propósito de los cuidados de la mujer. Cultura de los Cuidados. (Edición digital) 16(33):50-54.

- Galende, E. (2001) Sexo y amor: Anhelos e incertidumbres de la intimidad actual. Paidós, Buenos Aires

- Gunnings S. Bedford, A. (1864) Pablo Gentil (traducción). Imprenta de José M. Ducazal, Madrid

- Hernández Conesa, J. Ma (1995) Historia de la Enfermería. McGraw Hill- Interamericana, Madrid

- Jacquart, D; Tomasset, C; Adamson, M. (1990) Sexuality and Medicine in the Middle Ages Medical History 34(2): 218.

- Lamet, P. M; Ródenas, J. M; Gallego, D. (1968) Capítulo 5 en Lecciones de cine. Ed. Mensajero, Bilbao
- Nash, M; Tavera, S. (1995) Experiencias desiguales: Conflictos sociales y respuestas colectivas (s. XIX). Ed. Síntesis, Madrid: 58- 59

- Ortiz Gómez, T. (2002) El papel del género en la construcción histórica del conocimiento científico sobre la mujer, I Congreso Nacional "La salud de las mujeres: hacia la igualdad de género en salud" Ministerio de Trabajo y Asuntos sociales- Instituto de la Mujer. Madrid

- Scanzoni von Lichtenfels, F. W. (1862) Tratado práctico de las enfermedades de los órganos sexuales de la mujer. Carlos Builly- Bailliere (traducción). Librerías extranjera y nacional, científica y literaria, Madrid

- Polaino- Lorente, A. (1998) Sexo y Cultura: Análisis del comportamiento sexual. Ed. Rialp, Madrid

- Zabala Zapata, I. M. (1996) Feminismo y Literatura en Díaz Diazcaletz, M.; Zabala Zapata, I. Breve Historia feminista de la Literatura Española en Lengua Castellana. Anthropos, Barcelona 